\title{
Ameliorative effects of pomegranate on carbon tetrachloride hepatotoxicity in rats: A molecular and histopathological study
}

\author{
ZEIN SHABAN IBRAHIM ${ }^{1,2}$, MOHAMED ABDO NASSAN $^{3}$ and MOHAMED MOHAMED SOLIMAN ${ }^{4,5}$
}

${ }^{1}$ Department of Physiology, Faculty of Medicine, Taif University, Taif 888, Saudi Arabia; ${ }^{2}$ Department of Physiology, Faculty of Veterinary Medicine, Kaferelsheikh University, Kafrelsheikh 47321; ${ }^{3}$ Department of Pathology, Faculty of Veterinary Medicine, Zagazig University, Zagazig, Sharqia 44519, Egypt; ${ }^{4}$ Medical Laboratories Department, College of Applied Medical Sciences, Taif University, Turabah 311, Saudi Arabia; ${ }^{5}$ Department of Biochemistry, Faculty of Veterinary Medicine, Benha University, Moshtohor 13736, Egypt

Received April 1, 2015; Accepted February 2, 2016

DOI: $10.3892 / \mathrm{mmr} .2016 .4956$

\begin{abstract}
The present study aimed to investigate the molecular mechanism underlying the hepatoprotective effects of pomegranate (POM) against oxidative stress in a rat model of carbon tetrachloride $\left(\mathrm{CCl}_{4}\right)$-induced liver damage. Injection of rats with $\mathrm{CCl}_{4}$ resulted in hepatic inflammation and lipid accumulation via the upregulation of interleukin (IL)-6 and sterol regulatory element-binding protein 1c (SREBP-1c) mRNA expression. $\mathrm{CCl}_{4}$ induced downregulation of the anti-inflammatory factors alpha 2 -macroglobulin $(\alpha-2 \mathrm{M})$ and IL-10 in comparison with the POM treated group. In addition, $\mathrm{CCl}_{4}$ induced downregulation of superoxide dismutase (SOD), glutathione S-transferase (GST) and catalase (CAT) expression. Conversely, prior administration of POM counteracted the deleterious alterations induced by $\mathrm{CCl}_{4}$. $\mathrm{POM}$ downregulated $\mathrm{CCl}_{4}$-induced IL- 6 upregulation, normalized the increase in SREBP-1c expression, and prevented $\mathrm{CCl}_{4}$-induced $\alpha-2 \mathrm{M}$ downregulation. POM counteracted $\mathrm{CCL}_{4}$-induced alterations via immunosuppressive, anti-inflammatory and regenerative effects by upregulating transforming growth factor- $\beta 1$, HSP70 and IL-10 mRNA expression. In addition, POM increased reactive oxygen species scavenging activity
\end{abstract}

Correspondence to: Professor Mohamed Mohamed Soliman, Department of Biochemistry, Faculty of Veterinary Medicine, Benha University, Alkanal Street, Moshtohor 13736, Egypt

E-mail: mohamedsoliman8896@yahoo.com

Abbreviations: $\alpha-2 \mathrm{M}$, alpha 2-macroglobulin; CAT, catalase; GST, glutathione S-transferase; HSP70, heat shock protein 70; i.p., intraperitoneal injection; IL-6, interleukin-6; IL-10, interleukin-10; SOD, superoxide dismutase; ROS, reactive oxygen species; POM, pomegranate; SREBP-1c, sterol regulatory element-binding protein $1 \mathrm{c}$; TGF- $\beta 1$, transforming growth factor- $\beta 1$; RT-PCR, reverse transcription-polymerase chain reaction

Key words: pomegranate, carbon tetrachloride, protection, gene expression, hepatic toxicity by augmenting the antioxidant defense mechanism against $\mathrm{CCl}_{4}$ hepatotoxicity, as demonstrated by detecting SOD, CAT and GST expression. These results confirm that, at the molecular level, POM exerts hepatoprotective effects against $\mathrm{CCl}_{4}$-induced oxidative stress and liver tissue damage.

\section{Introduction}

Oxidative stress occurs due to the inability of various antioxidant mechanisms to scavenge excessive levels of reactive oxygen species (ROS) and/or a reduction in antioxidant defense mechanisms. Consequently, degenerative diseases, including hepatopathies (1) and nephropathies (2) may occur. The liver and kidneys are the first tissues to be affected by oxidative stress produced by infectious agents, alcohol, drugs, toxic industrial chemicals, food additives, and pollutants in the air and water. Furthermore, free radicals and ROS have a crucial role in the initiation and progression of liver disease and cancer (3).

Carbon tetrachloride $\left(\mathrm{CCl}_{4}\right)$ is an industrial solvent, which is extensively used as a xenobiotic to induce chemical liver injury. $\mathrm{CCl}_{4}$-induced oxidative stress is commonly used in rodent models to determine the protective effects of synthetic or natural products against drug-associated hepatotoxicity and nephrotoxicity $(4,5) . \mathrm{CCl}_{4}$ is metabolized by hepatic microsomal cytochrome $\mathrm{P} 450$ into trichloromethyl free radicals. Trichloromethyl can react with sulfhydryl groups (glutathione and protein thiols) and antioxidant enzymes, including catalase (CAT) and superoxide dismutase (SOD) (4). Overproduction of trichloromethyl free radicals may initiate membrane lipid peroxidation, eventually leading to various pathological alterations (6). ROS have an important role in the development and progression of human disease, including liver disorders, lung and kidney damage, diabetes mellitus, atherosclerosis and aging (7), via free radical-induced lipid peroxidation and cell membrane damage (8). Furthermore, $\mathrm{CCl}_{4}$ causes tissue damage during inflammation, cancer and aging (9). Parallel to oxidative stress, $\mathrm{CCl}_{4}$ may induce alterations in various pathways, which affect the metabolic and healthy state of subjects, including changes in the gene expression of acute phase proteins, cytokines (inflammatory and anti-inflammatory), and genes associated with lipid metabolism. 
It has previously been demonstrated that various natural products can protect organs against $\mathrm{CCl}_{4}$-induced oxidative stress by enhancing the activities of antioxidant enzymes, including CAT, glutathione S-transferase (GST) and SOD (10). Pomegranate (Punica granatum; POM) is widely renowned in the Middle East due to its health benefits (11). POM fruit, juice and peel possess a marked antioxidant capacity, exert anti-obesity and antihypertensive effects, and may be used to treat prostate cancer (12-14). POM contains high levels of polyphenols, particularly ellagitannins, condensed tannins and anthocyanins (15). POM juice consumption has been reported to significantly increase sperm quality, spermatogenic cell density, antioxidant activity and testosterone levels in male rats (16). In addition, POM juice has been proposed to exert chemopreventive, chemotherapeutic, antiatherosclerotic and anti-inflammatory effects $(14,17)$; therefore, its consumption has markedly increased $(18,19)$. It is well known that the liver is the main organ responsible for detoxification and drug metabolism; therefore, the present study aimed to investigate the effects of POM on $\mathrm{CCl}_{4}$-induced hepatotoxicity. In addition, the molecular mechanisms underlying the effects of POM on $\mathrm{CCl}_{4}$-induced alterations in the expression of antioxidants, cytokines, inflammatory markers and genes associated with lipid metabolism, as well as hepatic histopathology, were examined.

\section{Materials and methods}

Materials. $\mathrm{CCl}_{4}$ was purchased from Sigma-Aldrich (St. Louis, MO, USA). The DNA ladder (100 bp) was purchased from Thermo Fisher Scientific, Inc. (Waltham, MA, USA). QIAzol for RNA extraction and oligo-dT primers were purchased from Qiagen, Inc. (Valencia, CA, USA). Rabbit anti-rat heat shock protein 70 (HSP70) primary antibody was purchased from Santa Cruz Biotechnology, Inc. (Dallas, TX, USA).

Experimental animals. Male Wistar rats, weighing 200-250 g, were purchased from the Animal House, King Abdulaziz University (Jeddah, Saudi Arabia). The adult male Wistar rats were divided into four equal groups ( $n=6 /$ group) in the present study. The rats were kept under observation for $\sim 1$ week, in order to acclimate to the environment prior to onset of the experiment. The rats were maintained in stainless steel cages at normal atmospheric temperature $\left(27 \pm 5^{\circ} \mathrm{C}\right)$, under good ventilation and a $12 \mathrm{~h} / 12 \mathrm{~h}$ light/dark cycle. The rats had access to food and water ad libitum. All animal procedures were approved by the Ethics Committee of the Dean of Scientific Affairs of Taif University (Taif, Saudi Arabia).

Experimental design and treatments. Group 1 served as a control group, in which the rats were injected intraperitoneally (i.p.) with corn oil $(0.5 \mathrm{ml} / \mathrm{kg})$ once daily. Group 2 were administered water daily for 25 days and on days 18 and 20 were injected with $1 \mathrm{ml} / \mathrm{kg} \mathrm{CCl}_{4}$ (50\% in corn oil; i.p.). Group 3 were administered POM juice daily [30 $\mathrm{ml} / \mathrm{kg}$ body weight (BW)], and were injected with corn oil (i.p.) on days 18 and 20. Group 4 were administered POM juice ( $30 \mathrm{ml} / \mathrm{kg} \mathrm{BW}$ ) daily for 25 days, and were injected with $1 \mathrm{ml} / \mathrm{kg} \mathrm{CCl}_{4}$ (50\% in corn oil; i.p.) on days 18 and 20. POM juice was administered to the rats in the morning, $2 \mathrm{~h}$ after water deprivation, and the rats consumed the given dose within $2 \mathrm{~h}$, in order to assure no changes due to environmental conditions. The dose of POM juice was chosen based on a previous study (20).

Sampling. At the end of the experiment, the rats were sacrificed by cervical dislocation following anesthetization by diethyl ether (Sigma-Aldrich) inhalation. The liver tissues of all groups were harvested, homogenized and maintained in either formalin or QIAzol reagent for histopathology and RNA extraction, respectively.

\section{Analysis of gene expression}

RNA extraction and $c D N A$ synthesis. Total RNA was extracted from $100 \mathrm{mg}$ tissue samples using QIAzol reagent, according to the manufacturer's instructions. The integrity of the prepared RNA was determined by electrophoresis. RNA concentration and purity were determined spectrophotometrically at 260 and 280 nm (Bio-Rad SmartSpec Spectrophotometer; Bio-Rab Laboratories, Inc., Hercules, CA, USA). The 260/280 optical density ratio of all RNA samples was 1.7-1.9. A total of $2 \mu \mathrm{g}$ RNA was reverse transcribed using oligo-dT primers and Moloney murine leukaemia virus (M-MuLV) reverse transcriptase (SibEnzyme Ltd., Novosibirsk, Russia). For cDNA synthesis, a mixture of $2 \mu \mathrm{g}$ total RNA and $0.5 \mathrm{ng}$ oligo dT primer in a total volume of $11 \mu \mathrm{l}$ sterilized diethylpyrocarbonate (DEPC) water was incubated in a PeX 0.5 thermal Cycler (Bio-Rad Laboratories, Inc.) at $65^{\circ} \mathrm{C}$ for $10 \mathrm{~min}$ for denaturation. Then, $4 \mu 1$ 5X RT-buffer, $2 \mu 110 \mathrm{mM}$ dNTPs and 100 units M-MuLV Reverse Transcriptase (all purchased from SibEnzyme Ltd., Novosibirsk, Russia) was added in a total volume of $20 \mu 1$ by DEPC water. The mixture was re-incubated in the thermal cycler at $37^{\circ} \mathrm{C}$ for $1 \mathrm{~h}$, then at $90^{\circ} \mathrm{C}$ for $10 \mathrm{~min}$ in order to inactivate the enzyme.

Semi-quantitative reverse transcription-polymerase chain reaction $(R T-P C R)$. RNA from hepatic tissues was analyzed by semi-quantitative RT-PCR using corresponding specific primers for the indicated genes (Table I). The primers were designed using Oligo-4 computer program (version 7.0; Molecular Biology Insights, Cascade, CO, USA) according to the nucleotide sequences published in GenBank (http://www.ncbi.nlm.nih. gov/genbank/; Table I), and were synthesized by Macrogen Korea (Seoul, South Korea). PCR was conducted in a final volume of $25 \mu \mathrm{l}$ consisting of $1 \mu \mathrm{l}$ cDNA, $1 \mu \mathrm{l}$ (10 picomoles) of each primer (forward and reverse), and 12.5 $\mu \mathrm{l}$ PCR Master Mix (Promega Corporation, Madison, WI, USA). The final volume was brought to $25 \mu \mathrm{l}$ using sterilized, nuclease-free deionized water. PCR was carried out using a PeX 0.5 Thermal Cycler, and the following cycling conditions were used: Denaturation at $94^{\circ} \mathrm{C}$ for $5 \mathrm{~min}$ for one cycle, followed by 27 cycles of denaturation at $94^{\circ} \mathrm{C}$ for $1 \mathrm{~min}$, annealing at the specific temperature corresponding to each primer (Table I) for $1 \mathrm{~min}$, and extension at $72^{\circ} \mathrm{C}$ for $1 \mathrm{~min}$, followed by a final extension step at $72^{\circ} \mathrm{C}$ for $5 \mathrm{~min}$. As an internal reference, glyceraldehyde 3-phosphate dehydrogenase mRNA expression was detected using specific primers (Table I). PCR products subsequently underwent $1.5 \%$ agarose gel electrophoresis (Bio Basic Inc., Markham, ON, Canada) in Tris-Borate-ethylenediaminetetraacetic acid buffer at $100 \mathrm{~V}$ for 30 min with ethidium bromide staining (Sigma-Aldrich). PCR products were visualized under ultraviolet (UV) light and images 
Table I. Sequences and conditions of polymerase chain reaction primers.

\begin{tabular}{|c|c|c|c|c|c|}
\hline Gene & $\begin{array}{l}\text { Product } \\
\text { size (bp) }\end{array}$ & $\begin{array}{l}\text { Annealing } \\
\text { temp. }\left({ }^{\circ} \mathrm{C}\right)\end{array}$ & $\begin{array}{l}\text { Number of } \\
\text { PCR cycles }\end{array}$ & Direction & Sequence $\left(5^{\prime}-3^{\prime}\right)$ \\
\hline GST & 575 & 55 & 29 & $\begin{array}{c}\text { Sense } \\
\text { Antisense }\end{array}$ & $\begin{array}{l}\text { GCTGGAGTGGAGTTTGAAGAA } \\
\text { GTCCTGACCACGTCAACATAG }\end{array}$ \\
\hline SOD & 410 & 55 & 28 & $\begin{array}{c}\text { Sense } \\
\text { Antisense }\end{array}$ & $\begin{array}{l}\text { AGGATTAACTGAAGGCGAGCAT } \\
\text { TCTACAGTTAGCAGGCCAGCAG }\end{array}$ \\
\hline Catalase & 652 & 55.5 & 30 & $\begin{array}{c}\text { Sense } \\
\text { Antisense }\end{array}$ & $\begin{array}{l}\text { GCGAATGGAGAGGCAGTGTAC } \\
\text { GAGTGACGTTGTCTTCATTAGCACTG }\end{array}$ \\
\hline$\alpha-2 \mathrm{M}$ & 325 & 56 & 30 & $\begin{array}{c}\text { Sense } \\
\text { Antisense }\end{array}$ & $\begin{array}{l}\text { GCTCCTGTCTGTTTCCTTAGTT } \\
\text { ATTGGCCTTTCGTGGTTTAG }\end{array}$ \\
\hline IL-6 & 485 & 57 & 32 & $\begin{array}{c}\text { Sense } \\
\text { Antisense }\end{array}$ & $\begin{array}{l}\text { AGTTGCCTTCTTGGGACTGA } \\
\text { GAGCATTGGAAGTTGGGGTA }\end{array}$ \\
\hline IL-10 & 259 & 57 & 33 & $\begin{array}{c}\text { Sense } \\
\text { Antisense }\end{array}$ & $\begin{array}{l}\text { ACCAGCTGGACAACATACTGC } \\
\text { TCATTCTTCACСTGCTCСАСТ }\end{array}$ \\
\hline TGF- $\beta 1$ & 456 & 58 & 32 & $\begin{array}{c}\text { Sense } \\
\text { Antisense }\end{array}$ & $\begin{array}{l}\text { TGAGTGGCTGTCTTTTGACG } \\
\text { TGGTTGTAGAGGGCAAGGAC }\end{array}$ \\
\hline SREBP-1c & 191 & 58 & 33 & $\begin{array}{c}\text { Sense } \\
\text { Antisense }\end{array}$ & $\begin{array}{l}\text { GGAGCCATGGATTGCACATT } \\
\text { AGGAAGGCTTCCAGAGAGGA }\end{array}$ \\
\hline G3PDH & 309 & 52 & 25 & $\begin{array}{c}\text { Sense } \\
\text { Antisense }\end{array}$ & $\begin{array}{l}\text { AGATCCACAACGGATACATT } \\
\text { TCCCTCAAGATTGTCAGCAA }\end{array}$ \\
\hline
\end{tabular}

GST, glutathione S-transferase; SOD, superoxide dismutase; AGP, ; $\alpha-2 \mathrm{M}$, alpha 2-macroglobulin; IL, interleukin; TGF- $\beta 1$, transforming growth factor- $\beta 1$; FAS, ; SREBP-1c, sterol regulatory element-binding protein 1c; G3PDH, glyceraldehyde 3-phosphate dehydrogenase.

were captured using an InGenius 3.0 gel documentation system (Syngene, Frederick, MD, USA). Band intensities from the various rats from each group were quantified densitometrically using ImageJ software version 1.47 (http://imagej.en.softonic. com/).

Immunohistochemical staining of HSP70. Tissue sections were deparaffinized and were then treated with $3 \% \mathrm{H}_{2} \mathrm{O}_{2}$ for $10 \mathrm{~min}$, in order to inactivate peroxidases. Subsequently, the sections were heated in $10 \mathrm{mM}$ citrate buffer at $121^{\circ} \mathrm{C}$ for $30 \mathrm{~min}$ for antigen retrieval, blocked in 5\% normal serum for $20 \mathrm{~min}$, and were incubated with primary polyclonal anti-HSP70 [1:100 in phosphate-buffered saline (PBS); sc-33575; Santa Cruz Biotechnology,Inc.] overnightat $4^{\circ} \mathrm{C}$. Afterthree extensive washes with PBS, sections were incubated with a biotin-conjugated goat anti-rabbit secondary antibody (1:2,000 in PBS; sc-2040; Santa Cruz Biotechnology, Inc.) for $20 \mathrm{~min}$ at $32^{\circ} \mathrm{C}$. Following a further incubation with horseradish peroxidase-labeled streptavidin (Santa Cruz Biotechnology, Inc.) according to the manufacturer's instructions, antibody binding was visualized with diaminobenzidine (Sigma-Aldrich) and sections were counterstained with hematoxylin (Sigma-Aldrich). Tissue slides were visualized using a Wolfe S9-0982 microscope (Carolina Biological Supply Co., Burlington, NC, USA) and photos were captured using a Canon Power Shot SX500 IS digital camera (Canon, Tokyo, Japan).

Statistical analysis. Data are presented as the mean \pm standard error of the mean. Statistical analysis for the obtained results was conducted using one-way analysis of variance followed by the least significant difference test for multiple comparisons among groups. The analysis was performed using SPSS version 13.0 (SPSS Inc., Chicago, IL, USA). P $<0.05$ was considered to indicate a statistically significant difference.

\section{Results}

Effects of POM on the hepatic mRNA expression levels of interleukin (IL)-6, sterol regulatory element-binding protein $1 c$ (SREBP-1c) and alpha 2-macroglobulin $(\alpha-2 M)$. To examine whether POM was able to modulate cytokine expression in order to exert its hepatoprotective effects, the mRNA expression levels of IL-6 were detected (Fig. 1A). The mRNA expression levels of IL6 were upregulated following $\mathrm{CCl}_{4}$ injection. Furthermore, when administered alongside $\mathrm{CCl}_{4}$, POM normalized the expression of IL6 mRNA. In addition, SREBP-1c, a lipogenic transcription factor and key regulator of hepatic lipid metabolism, was detected. The mRNA expression levels of SREBP-1 were significantly upregulated following $\mathrm{CCl}_{4}$ injection $(\mathrm{P}<0.05)$. Furthermore, when administered alongside $\mathrm{CCl}_{4}$, POM completely normalized SREBP-1c mRNA expression (Fig. 1B). $\alpha-2 \mathrm{M}$ is known to stabilize target protein and enhance its regeneration. In the present study, $\alpha-2 \mathrm{M}$ expression was significantly downregulated in the $\mathrm{CCl}_{4}$ group compared with the control $(\mathrm{P}<0.05)$. However, treatment with POM increased $\alpha-2 \mathrm{M}$ mRNA expression. Concurrent POM administration in the $\mathrm{CCl}_{4}$-injected group resulted in a further upregulation in $\alpha-2 \mathrm{M}$ expression (Fig. 1C). 
A
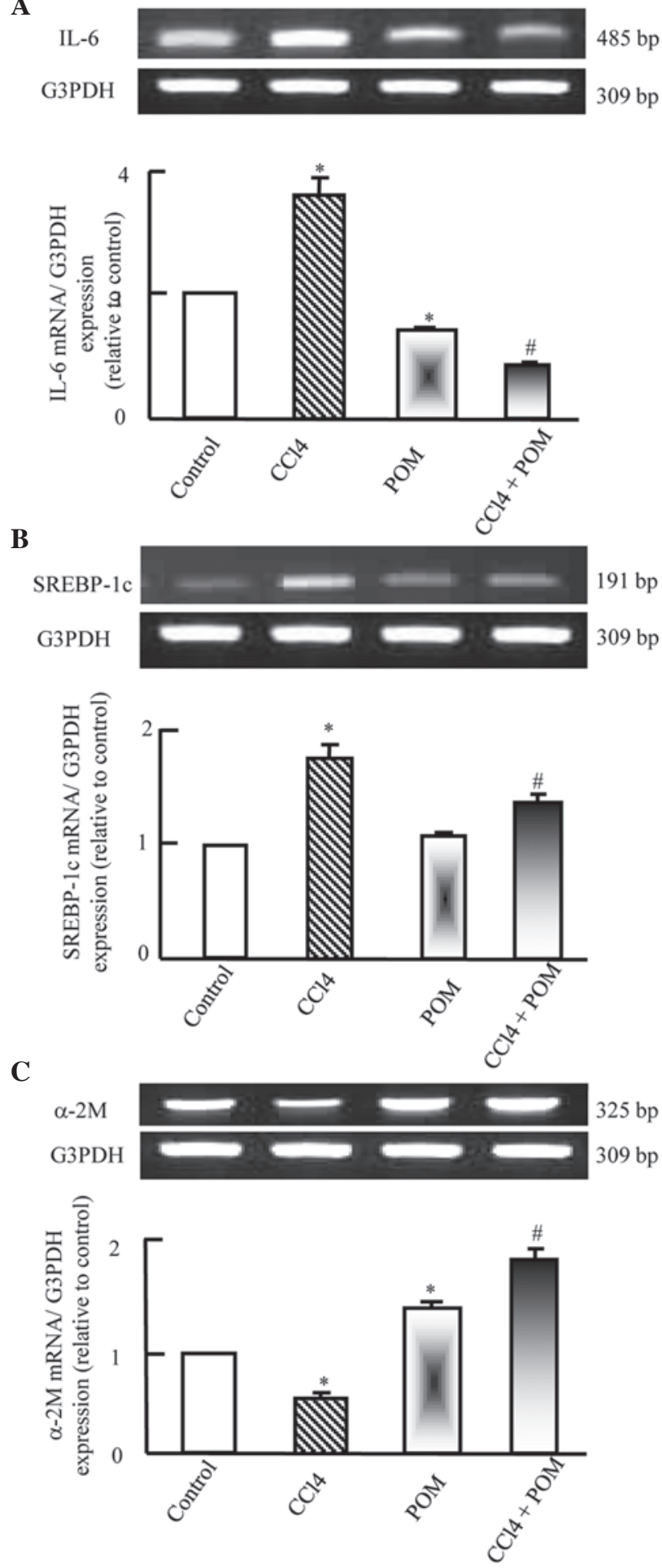

Figure 1. Semi-quantitative reverse transcription-polymerase chain reaction analysis of (A) interleukin (IL)-6, (B) sterol regulatory element-binding protein 1c (SREBP-1c) and (C) alpha 2-macroglobulin ( $\alpha$-2M) mRNA expression in the liver. Glyceraldehyde 3-phosphate dehydrogenase (G3PDH) was used as an internal reference. Experimental groups were administered corn oil as a control, carbon tetrachloride $\left(\mathrm{CCl}_{4}\right)$, pomegranate $(\mathrm{POM})$, or $\mathrm{CCl}_{4}$ plus $\mathrm{POM}$. Data are presented as the mean \pm standard error of the mean obtained from three independent experiments. ${ }^{*} \mathrm{P}<0.05$ vs. the control group; ${ }^{\text {}} \mathrm{P}<0.05$ vs. the $\mathrm{CCl}_{4}$ group.

Effects of POM on the mRNA expression levels of transforming growth factor (TGF)- $\beta 1$ and IL-10. The mRNA expression levels of TGF- $\beta 1$ were significantly upregulated
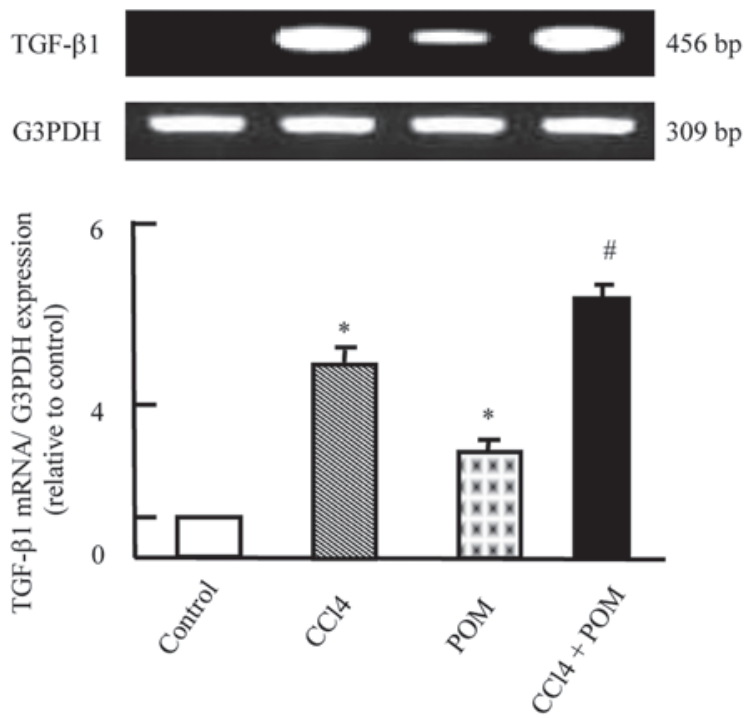

B
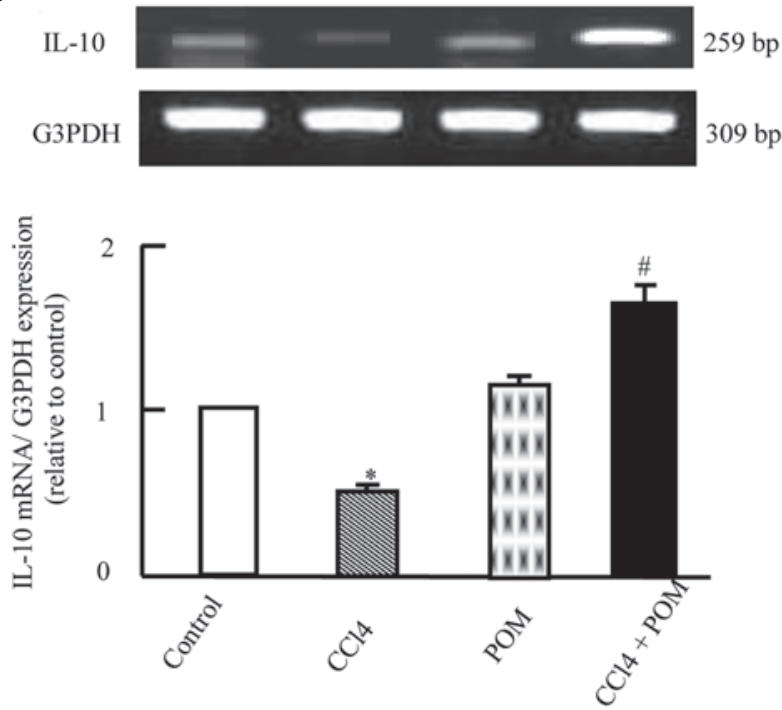

Figure 2. Semi-quantitative reverse transcription-polymerase chain reaction analysis of (A) transforming growth factor (TGF)- $\beta 1$ and (B) interleukin (IL)-10 mRNA expression in the liver. Glyceraldehyde 3-phosphate dehydrogenase (G3PDH) was used as an internal reference. Experimental groups were administered corn oil as a control, carbon tetrachloride $\left(\mathrm{CCl}_{4}\right)$, pomegranate $(\mathrm{POM})$, or $\mathrm{CCl}_{4}$ plus POM. Data are presented as the mean \pm standard error of the mean obtained from three independent experiments. "P<0.05 vs. the control group; ${ }^{*} \mathrm{P}<0.05$ vs. the $\mathrm{CCl}_{4}$ group.

in the $\mathrm{CCl}_{4}$-treated group compared with in the control group $(\mathrm{P}<0.05)$. POM treatment alone only slightly upregulated TGF- $\beta 1$ mRNA expression, as compared with the control group. However, when the rats were co-treated with $\mathrm{CCl}_{4}$ and $\mathrm{POM}$ the mRNA expression levels of TGF- $\beta 1$ were further significantly upregulated compared with in the $\mathrm{CCl}_{4}$ group ( $\mathrm{P}<0.05$; Fig. 2A). Treatment of the rats with $\mathrm{CCl}_{4}$ significantly suppressed the mRNA expression levels of the anti-inflammatory cytokine IL-10, as compared with the control $(\mathrm{P}<0.05)$. However, co-treatment with $\mathrm{POM}$ and $\mathrm{CCl}_{4}$ significantly upregulated interleukin-10 mRNA expression compared with the control and $\mathrm{CCl}_{4}$-treated groups $(\mathrm{P}<0.05$; Fig. $2 \mathrm{~B})$.

Effects of POM on hepatic antioxidant enzyme expression $\mathrm{CCl}_{4}$ induced the downregulation of the expression of CAT, GST 

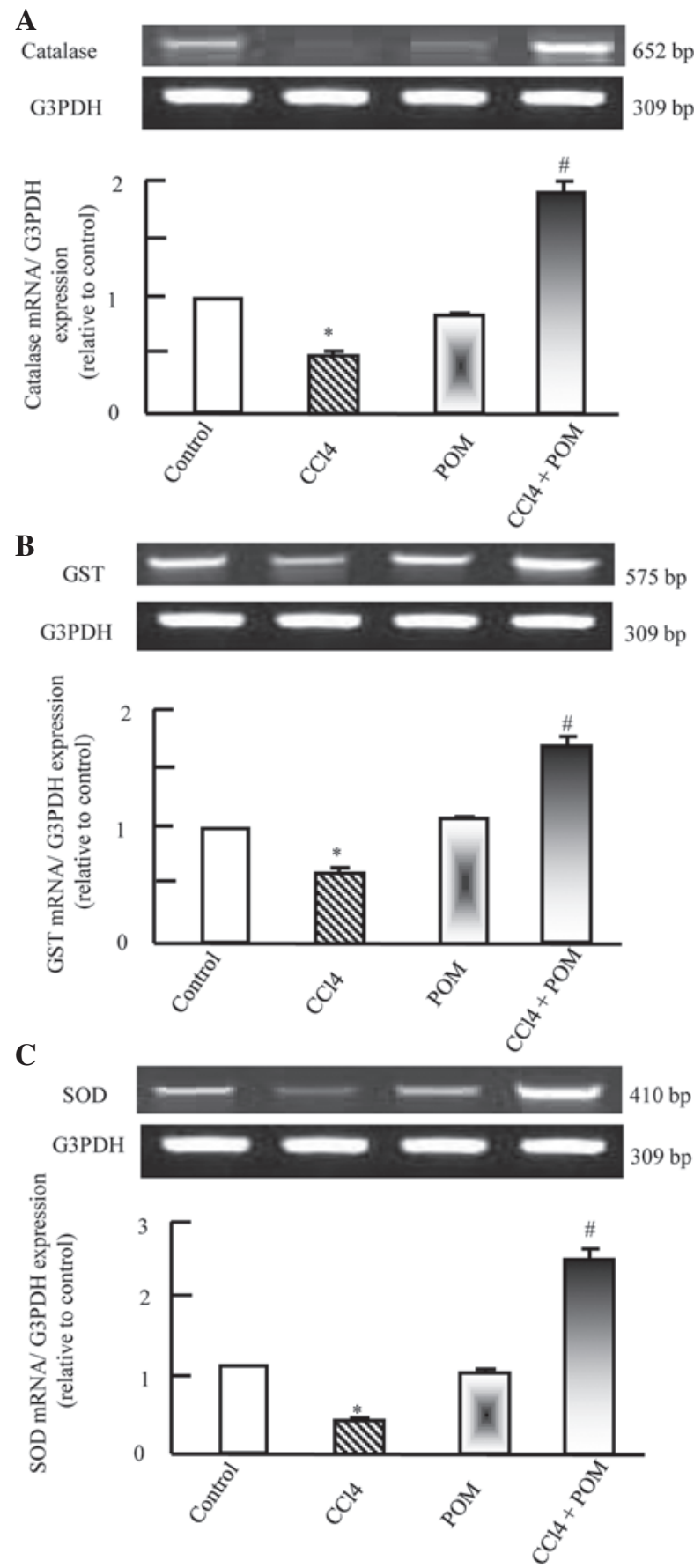

Figure 3. Semi-quantitative reverse transcription-polymerase chain reaction analysis of (A) catalase, (B) glutathione S-transferase (GST) and (C) superoxide dismutase (SOD) mRNA expression in the liver. Glyceraldehyde 3-phosphate dehydrogenase (G3PDH) was used as an internal reference. Experimental groups were administered corn oil as a control, carbon tetrachloride $\left(\mathrm{CCl}_{4}\right)$, pomegranate $(\mathrm{POM})$, or $\mathrm{CCl}_{4}$ plus POM. Data are presented as the mean \pm standard error of the mean obtained from three independent experiments. ${ }^{*} \mathrm{P}<0.05$ vs. the control group; ${ }^{\#} \mathrm{P}<0.05$ vs. the $\mathrm{CCl}_{4}$ group.

and SOD, which were normalized following co-administration of POM with $\mathrm{CCl}_{4}$. Following co-treatment with $\mathrm{CCl}_{4}$ and POM, the mRNA expression levels of the antioxidant enzymes were completely restored, compared with in the $\mathrm{CCl}_{4}$ group (Fig. 3A-C).

Effects of POM on hepatic HSP7O, as revealed by immunohistochemical staining. Immunostaining of liver samples from control rats with HSP70 antibodies indicated normal hepatic architecture, with normal hepatic cords, hepatic sinusoids and normal portal area, and an absence of HSP70 expression (Fig. 4A). Liver samples from the $\mathrm{CCl}_{4}$ group exhibited moderate HSP70 expression in the hepatocytes with increased fat infiltration (Fig. 4B). Liver samples from the POM-supplemented group exhibited a lack of HSP70 expression in hepatocytes, alongside normal hepatic architecture (Fig. 4C). Liver samples from the rats co-treated with $\mathrm{CCl}_{4}$ and POM exhibited significantly increased HSP70 expression in the hepatocytes $(\mathrm{P}<0.05)$, alongside a decrease in the aberrant alterations detected in the $\mathrm{CCl}_{4}$ group (Fig. 4D).

\section{Discussion}

The present study demonstrated that $\mathrm{POM}$ exerted a protective effect on the liver against $\mathrm{CCl}_{4}$-induced oxidative stress. $\mathrm{CCl}_{4}$ is one of the most commonly used hepatotoxins, and its metabolites trichloromethyl radical $\left(\mathrm{CCl}_{3}\right)$ and trichloromethyl peroxy radical $\left(\mathrm{Cl}_{3} \mathrm{COO} \bullet\right)$ are involved in the pathogenesis of liver and kidney damage $(7,21)$. Both radicals are able to covalently bind macromolecules and induce peroxidative degradation of the cell membrane of liver cells.

IL-6 is produced in the liver by several types of cells, including biliary epithelial cells and cholangiocytes, in response to inflammatory mediators $(22,23)$. IL-6 is a commonly used marker of inflammation, the expression of which has been demonstrated to be markedly increased in the liver of patients with non-alcoholic fatty liver disease and non-alcoholic steatohepatitis (24). In the present study, $\mathrm{CCl}_{4}$ induced inflammation, as demonstrated by an upregulation in hepatic IL-6 expression. However, downregulation of basal IL-6 mRNA expression levels, and attenuation of the $\mathrm{CCl}_{4}$-induced upregulation of IL- 6 by POM, indicates its anti-inflammatory effects. Parallel with these results, increased levels of the proinflammatory cytokine IL-6 in the ileum of a rat model of necrotizing enterocolitis were normalized following treatment with POM seed oil (25).

SREBP-1c is an important transcription factor, which regulates the hepatic expression of enzymes associated with the de novo synthesis of fatty acids (26). Upregulation of the gene expression levels of SREBP-1c has previously been shown to accompany ethanol-induced fatty liver (27). In the present study, $\mathrm{CCl}_{4}$ induced the upregulation of SREBP-1c mRNA expression, thus indicating the disturbance of lipid metabolism through which $\mathrm{CCl}_{4}$ may induce liver degeneration. In addition, treatment with POM normalized SREBP-1c hepatic mRNA expression, thus suggesting that the hepatoprotective effects of POM operate via normalization of lipid metabolism. Consistently, a previous study demonstrated that strawberry seed oil was able to decrease SREBP-1c hepatic content, which was associated with reduced plasma triglycerides and a decreased proportion of liver fat (28).

$\alpha-2 \mathrm{M}$ is the largest major non-immunoglobulin plasma protein, which is synthesized by numerous cell lineages, including lung fibroblasts, monocytes, macrophages, hepatocytes, astrocytes and adrenocortical cells (29). $\alpha-2 \mathrm{M}$ is expressed in hepatocytes where it has an important role in the regulation of proteolytic activity in the tissue and pericellular space, and contributes to the clearance of $\alpha-2 \mathrm{M}$-proteinase complexes 
A

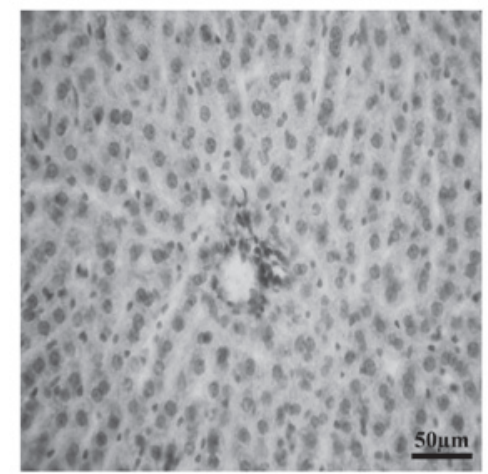

C

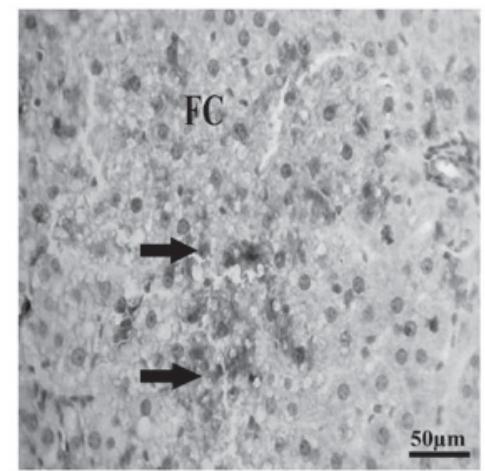

B

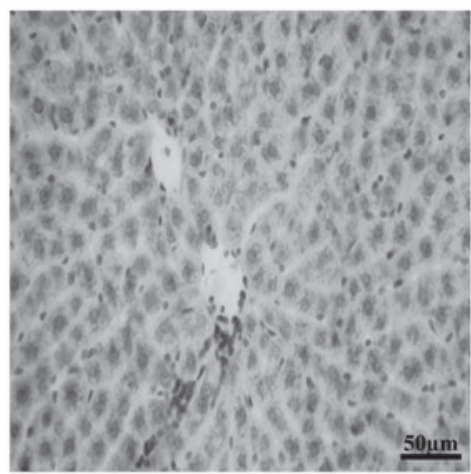

D

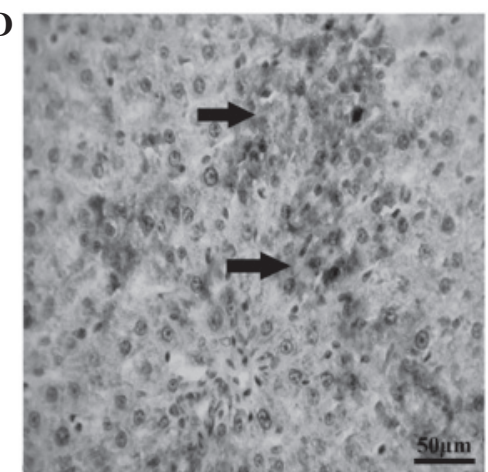

Figure 4. (A) Photomicrograph of a liver sample from a healthy control rat immunostained with heat shock protein 70 (HSP70). HSP70 expression was absent in the hepatocytes, and the sample exhibited normal hepatic cords, hepatic sinusoids (HS) and normal portal area. (B) Photomicrograph of a liver sample from a rat in the carbon tetrachloride $\left(\mathrm{CCl}_{4}\right)$ group immunostained with HSP70. Moderate HSP70 expression was detected in the hepatocytes (arrows) with extensive fatty changes (FC). (C) Photomicrograph of a liver sample from a pomegranate-treated rat immunostained with HSP70. HSP70 expression was absent in the hepatocytes, and the sample exhibited normal hepatic cords and HS. (D) Photomicrograph of a liver sample from a rat treated with $\mathrm{CCl}_{4}$ and pomegranate immunostained with HSP70. Strong HSP70 expression was detected in the hepatocytes alongside regeneration of the degenerative changes. Scale bar=50 $\mu \mathrm{m}$.

from the circulation (30). In addition, $\alpha-2 \mathrm{M}$ exerts an inhibitory effect on various types of nonspecific proteases and possesses pronounced immunosuppressive activity (31). The results of the present study demonstrated that treatment with $\mathrm{CCl}_{4}$ resulted in downregulation of hepatic $\alpha-2 \mathrm{M}$ mRNA expression compared with the control group. The ability of POM to upregulate basal and $\mathrm{CCl}_{4}$-suppressed $\alpha$-2M mRNA expression indicated that the hepatoprotective effects of POM may operate via upregulation of $\alpha-2 M$ expression. Notably, increased $\alpha-2 M$ levels have been reported to have an important role in radioprotection via anti-fibrotic, anti-inflammatory, antioxidant, homeostatic, and repair and remodeling mechanisms (32).

TGF- $\beta 1$ is a powerful pleiotropic cytokine that possesses immune-suppressing and anti-inflammatory properties (33). In the present study, treatment with POM alone elevated TGF- $\beta 1$ mRNA expression levels, thus indicating that the modulatory effects of POM on immune status may be caused by TGF- $\beta 1$ upregulation. Treatment with $\mathrm{CCl}_{4}$ induced the upregulation of TGF- $\beta 1$ mRNA expression, the expression of which was further upregulated in the rats co-treated with $\mathrm{POM}$ and $\mathrm{CCl}_{4}$. These results suggested that the anti-inflammatory effects of POM may be due to TGF- $\beta 1$ upregulation. In patient-tolerated kidney or liver allografts, type 1 regulatory $\mathrm{T}$ cells were demonstrated to exist, and were capable of suppressing naïve T-cell activation and producing high levels of both IL-10 and TGF- $\beta 1$ (34).

IL-10 has been reported to exert both pro- and antitumoral effects through the inhibition of nuclear factor- $\kappa \mathrm{B}$ signaling; therefore, it is able to downregulate proinflammatory cytokine expression (35). IL-10 configures development of the immune response and suppresses proinflammatory cytokine expression (36). In addition, IL-10 induces the downregulation of T helper 1 cytokine mRNA expression, and inhibits IL-1 and IL- 6 production $(37,38)$. In the present study, $\mathrm{CCl}_{4}$-induced downregulation of IL-10 is consistent with the findings of a previous study, which reported that $\mathrm{CCl}_{4}$ reduced hepatic IL-10 expression, as compared with in the control group (39). In the present study, POM upregulated IL-10 expression, thus suggesting that POM exerts an anti-inflammatory effect, which protects the liver from $\mathrm{CCl}_{4}$-induced inflammation. Notably, previous studies have reported that IL-10 may exert anti-fibrotic effects during $\mathrm{CCl}_{4}$-induced hepatic fibrosis $(40,41)$. Therefore, POM may protect the liver from $\mathrm{CCl}_{4}$-induced inflammation and fibrosis by upregulating the expression of IL-10 (42).

Delaying or inhibiting the oxidation of easily oxidizable macromolecules, such as lipids, is accomplished by antioxidants, including SOD, CAT and GST, which have a major role in protecting these molecules from the actions of free radicals or ROS (43). Conversion of superoxide to less toxic $\mathrm{H}_{2} \mathrm{O}_{2}$ is catalyzed by SOD, whereas conversion of $\mathrm{H}_{2} \mathrm{O}_{2}$ into nontoxic $\mathrm{H}_{2} \mathrm{O}$ is catalyzed by CAT (44). The present study demonstrated that administration of $\mathrm{POM}$ in $\mathrm{CCl}_{4}$-administered rats significantly restored mRNA expression of the antioxidants examined, thus suggesting that POM possesses anti-lipid peroxidation and antioxidative properties. Parallel with these results, Ocimum sanctum extract has been shown to cause a significant decrease in lipid peroxidation, coupled with a 
significant increase in SOD and CAT expression in the liver homogenates of rats exposed to oxidative stress (45). The present study suggested that $\mathrm{CCl}_{4}$-induced suppression of SOD mRNA expression may be caused by enhancement of lipid peroxidation or inactivation of antioxidant enzymes, which leads to increased accumulation of superoxide radicals and lipid peroxidation acceleration. However, when administered alongside $\mathrm{CCl}_{4}, \mathrm{POM}$ prevented $\mathrm{CCl}_{4}$-induced antioxidant suppression. These results indicated that the ROS scavenging activities of POM juice may protect the liver from $\mathrm{CCl}_{4}$-induced oxidative stress. A similar protective effect of flavonoids has been reported in a previous study, which detected the ability of flavonoids to scavenge oxidative radicals in the liver of mice and rats following exposure to $\mathrm{CCl}_{4}$ (46). In accordance with the present results, POM has been reported to exhibit a promising antioxidant capacity, and is an effective scavenger for several ROS, primarily due to its high levels of phenolic acids, flavonoids and other polyphenolic compounds (47), through which POM may protect against free radical-mediated oxidative stress and attenuate $\mathrm{CCL}_{4}$-induced antioxidant depletion (48).

HSPs are induced in response to various stressors, in order to protect cells from such effects (49). HSP70 has been reported to protect cells from tumor necrosis factor- $\alpha$, prostaglandin, hydrogen peroxide, ethanol and UV (50). In the present study, HSP70 expression was slightly increased following treat $\neg$ ment with $\mathrm{CCl}_{4}$, which is parallel to the previously reported induction of HSP70 in acute liver damage by $\mathrm{CCl}_{4}$ (51). POM administration, together with $\mathrm{CCl}_{4}$, induced strong HSP70 immunoreactivity, thus preventing protein denaturation, which may act as a mechanism to overcome $\mathrm{CCl}_{4}$-induced hepatic oxidative stress. Parallel with this assumption, $\mathrm{CCl}_{4}$-induced liver damage has been shown to be attenuated by pre-induction of chaperones by heat treatment (52).

In conclusion, the present study confirmed that POM exerts hepatoprotective effects against $\mathrm{CCl}_{4}$-induced oxidative stress. POM was demonstrated to possess anti-inflammatory effects by suppressing $\mathrm{CCl}_{4}$-induced IL-6 expression, and was able to normalize lipid peroxidation by decreasing $\mathrm{CCl}_{4}$-induced SREBP-1c expression and increasing $\mathrm{CCl}_{4}$-suppressed $\alpha-2 \mathrm{M}$ mRNA expression. In addition, POM may exert hepatoprotective activity by its immunosuppressive, anti-inflammatory and regenerative effects via upregulation of TGF- $\beta 1$, HSP70 and IL-10, and may increase ROS scavenging activities by augmenting the antioxidant defense mechanism against $\mathrm{CCl}_{4}$-induced hepatotoxicity and preventing $\mathrm{CCl}_{4}$-induced $\mathrm{SOD}, \mathrm{CAT}$ and GST downregulation.

\section{Acknowledgements}

The present study was supported by a research project grant (no. 1/436/3989) from Taif University (Taif, Saudi Arabia).

\section{References}

1. Hensley K, Robinson KA, Gabbita SP, Salsman S and Floyd RA: Reactive oxygen species, cell signaling and cell injury. Free Radic Biol Med 28: 1456-1462, 2000.

2. Ateşşahin A, Karahan I, Yilmaz S, Ceribaşi AO and Princci I: The effect of manganese chloride on gentamicin-induced nephrotoxicity in rats. Pharmacol Res 48: 637-642, 2003.
3. Jemal A, Siegel R, Ward E, Murray T, Xu J and Thun MJ: Cancer statistics, 2007. CA Cancer J Clin 57: 43-66, 2007.

4. Khan RA, Khan MR and Sahreen S: $\mathrm{CCl}_{4}$-induced hepatotoxicity: Protective effect of rutin on p53, CYP2E1 and the antioxidative status in rat. BMC Complement Altern Med 12: 178, 2012.

5. Es Haghi M, Dehghan G, Banihabib N, Zare S, Mikaili P and Panahi F: Protective effects of Cornus mas fruit extract on carbon tetrachloride induced nephrotoxicity in rats. Indian J Nephrol 24: 291-296, 2014.

6. Cemek M, Aymelek F, Büyükokuroğlu ME, Karaca T, Büyükben A and Yilmaz F: Protective potential of Royal Jelly against carbon tetrachloride induced-toxicity and changes in the serum sialic acid levels. Food Chem Toxicol 48: 2827-2832, 2010.

7. Singh K, Khanna AK and Chander R: Hepatoprotective activity of ellagic acid against carbon tetrachloride induced hepatotoxicity in rats. Indian J Exp Biol 37: 1025-1026, 1999.

8. Ogeturk M, Kus I, Kavakli A, Oner J, Kukner A and Sarsilmaz M: Reduction of carbon tetrachloride-induced nephropathy by melatonin administration. Cell Biochem Funct 23: 85-92, 2005.

9. Bhadauria M, Nirala SK, Shrivastava S, Sharma A, Johri S, Chandan BK, Singh B, Saxena AK and Shukla S: Emodin reverses $\mathrm{CCl}$ induced hepatic cytochrome $\mathrm{P} 450$ (CYP) enzymatic and ultrastructural changes: The in vivo evidence. Hepatol Res 39: 290-300, 2009.

10. Rajesh MG and Latha MS: Preliminary evaluation of the antihepatotoxic activity of Kamilari, a polyherbal formulation. J Ethnopharmacol 91: 99-104, 2004.

11. Al-Olayan EM, El-Khadragy MF, Metwally DM and Abdel Moneim AE: Protective effects of pomegranate (Punica granatum) juice on testes against carbon tetrachloride intoxication in rats. BMC Complement Altern Med 14: 164, 2014.

12. Ahmed MM, Samir el-SA, El-Shehawi AM and Alkafafy ME: Anti-obesity effects of Taif and Egyptian pomegranates: Molecular study. Biosci Biotechnol Biochem 79: 598-609, 2015.

13. Kaur G, Jabbar Z, Athar M and Alam MS: Punica granatum (pomegranate) flower extract possesses potent antioxidant activity and abrogates Fe-NTA induced hepatotoxicity in mice. Food Chem Toxicol 44: 984-993, 2006.

14. Malik A, Afaq F, Sarfaraz S, Adhami VM, Syed DN and Mukhtar H: Pomegranate fruit juice for chemoprevention and chemotherapy of prostate cancer. Proc Natl Acad Sci USA 102: 14813-14818, 2005.

15. Seeram NP, Adams LS, Henning SM, Niu Y, Zhang Y, Nair MG and Heber D: In vitro antiproliferative, apoptotic and antioxidant activities of punicalagin, ellagic acid and a total pomegranate tannin extract are enhanced in combination with other polyphenols as found in pomegranate juice. J Nutr Biochem 16: 360-367, 2005.

16. Türk G, Sönmez M, Aydin M, Yüce A, Gür S, Yüksel M, Aksu EH and Aksoy $\mathrm{H}$ : Effects of pomegranate juice consumption on sperm quality, spermatogenic cell density, antioxidant activity and testosterone level in male rats. Clin Nutr 27: 289-296, 2008.

17. Rozenberg O, Howell A and Aviram M: Pomegranate juice sugar fraction reduces macrophage oxidative state, whereas white grape juice sugar fraction increases it. Atherosclerosis 188: 68-76, 2006.

18. Mertens-Talcott SU, Jilma-Stohlawetz P, Rios J, Hingorani L and Derendorf $\mathrm{H}$ : Absorption, metabolism and antioxidant effects of pomegranate (Punica granatum L.) polyphenols after ingestion of a standardized extract in healthy human volunteers. J Agric Food Chem 54: 8956-8961, 2006.

19. Faria A, Monteiro R, Mateus N, Azevedo I and Calhau C: Effect of pomegranate (Punica granatum) juice intake on hepatic oxidative stress. Eur J Nutr 46: 271-278, 2007.

20. Adhami VM, Siddiqui IA, Syed DN, Lall RK and Mukhtar H: Oral infusion of pomegranate fruit extract inhibits prostate carcinogenesis in the TRAMP model. Carcinogenesis 33: 644-651, 2012.

21. Srivastava SP, Chen NQ and Holtzman JL: The in vitro $\mathrm{NADPH}$-dependent inhibition by $\mathrm{CCl}_{4}$ of the ATP-dependent calcium uptake of hepatic microsomes from male rats. Studies on the mechanism of inactivation of the hepatic microsomal calcium pump by the $\mathrm{CCl}_{3}$.radical. J Biol Chem 265: 8392-8399, 1990. 
22. Hirano T: Interleukin 6 and its receptor: Ten years later. Int Rev Immunol 16: 249-284, 1998

23. Park J, Gores GJ and Patel T: Lipopolysaccharide induces cholangiocyte proliferation via an interleukin-6-mediated activation of $\mathrm{p} 44 / \mathrm{p} 42$ mitogen-activated protein kinase. Hepatology 29: 1037-1043, 1999.

24. Wieckowska A, Papouchado BG, Li Z, Lopez R, Zein NN and Feldstein AE: Increased hepatic and circulating interleukin-6 levels in human nonalcoholic steatohepatitis. Am J Gastroenterol 103: 1372-1379, 2008.

25. Coursodon-Boyiddle CF, Snarrenberg CL, Adkins-Rieck CK, Bassaganya-Riera J, Hontecillas R, Lawrence P, Brenna JT, Jouni ZE and Dvorak B: Pomegranate seed oil reduces intestinal damage in a rat model of necrotizing enterocolitis. Am J Physiol Gastrointest Liver Physiol 303: G744-G751, 2012.

26. Strable MS and Ntambi JM: Genetic control of de novo lipogenesis: Role in diet-induced obesity. Crit Rev Biochem Mol Biol 45: 199-214, 2010.

27. Liu J, Takase I, Hakucho A, Okamura N and Fujimiya T: Carvedilol attenuates the progression of alcohol fatty liver disease in rats. Alcohol Clin Exp Res 36: 1587-1599, 2012.

28. Jurgoński A, Fotschki B and Juśkiewicz J: Dietary strawberry seed oil affects metabolite formation in the distal intestine and ameliorates lipid metabolism in rats fed an obesogenic diet. Food Nutr Res 59: 26104, 2015.

29. Sottrup-Jensen L: Alpha-macroglobulins: Structure, shape, and mechanism of proteinase complex formation. J Biol Chem 264 $11539-11542,1989$.

30. Strickland DK, Kounnas MZ and Argraves WS: LDL receptor-related protein: A multiligand receptor for lipoprotein and proteinase catabolism. FASEB J 9: 890-898, 1995.

31. Acosta JA, Hoyt DB, Schmid-Schönbein GW, Hugli TE, Anjaria DJ, Frankel DA and Coimbra R: Intraluminal pancreatic serine protease activity, mucosal permeability, and shock: A review. Shock 26: 3-9, 2006

32. Chen X, Kong X, Zhang Z, Chen W, Chen J, Li H, Cao W, Ge Y and Fang S: Alpha-2-macroglobulin as a radioprotective agent: A review. Chin J Cancer Res 26: 611-621, 2014.

33. Landskron G, De la Fuente M, Thuwajit $P$, Thuwajit $C$ and Hermoso MA: Chronic inflammation and cytokines in the tumor microenvironment. J Immunol Res 2014: 149185, 2014.

34. VanBuskirk AM, Burlingham WJ, Jankowska-Gan E, Chin T, Kusaka S, Geissler F, Pelletier RP and Orosz CG: Human allograft acceptance is associated with immune regulation. J Clin Invest 106: 145-155, 2000.

35. Schottelius AJ, Mayo MW, Sartor RB and Baldwin AS Jr: Interleukin-10 signaling blocks inhibitor of kappaB kinase activity and nuclear factor kappaB DNA binding. J Biol Chem 274: 31868-31874, 1999.

36. Moore KW, de Waal Malefyt R, Coffman RL and O'Garra A Interleukin-10 and the interleukin-10 receptor. Annu Rev Immunol 19: 683-765, 2001.

37. Fiorentino DF, Zlotnik A, Mosmann TR, Howard M and O'Garra A: IL-10 inhibits cytokine production by activated macrophages. J Immunol 147: 3815-3822, 1991.
38. Soliman MM, Abdo Nassan $M$ and Ismail TA: Immunohistochemical and molecular study on the protective effect of curcumin against hepatic toxicity induced by paracetamol in Wistar rats. BMC Complement Altern Med 14: 457, 2014

39. Hou YL, Tsai YH, Lin YH and Chao JC: Ginseng extract and ginsenoside $\mathrm{Rb} 1$ attenuate carbon tetrachloride-induced liver fibrosis in rats. BMC Complement Altern Med 14: 415, 2014.

40. Huang YH, Shi MN, Zheng WD, Zhang LJ, Chen ZX and Wang XZ: Therapeutic effect of interleukin-10 on $\mathrm{CCl}_{4}$-induced hepatic fibrosis in rats. World J Gastroenterol 12: 1386-1391, 2006.

41. Zhang LJ, Zheng WD, Chen YX, Huang YH, Chen ZX, Zhang SJ, Shi MN and Wang XZ: Antifibrotic effects of interleukin-10 on experimental hepatic fibrosis. Hepatogastroenterology 54: 2092-2098, 2007.

42. Pestka S, Krause CD, Sarkar D, Walter MR, Shi Y and Fisher PB: Interleukin-10 and related cytokines and receptors. Annu Rev Immunol 22: 929-979, 2004.

43. Ramnath V, Rekha PS and Sujatha KS: Amelioration of heat stress induced disturbances of antioxidant defense system in chicken by brahma rasayana. Evid Based Complement Alternat Med 5: 77-84, 2008.

44. Celi P: The role of oxidative stress in small ruminants health and production. R Bras Zootec 39:348-363, 2010.

45. Ramesh B and Satakopan VN: Antioxidant activities of hydroalcoholic extract of Ocimum sanctum against cadmium Induced toxicity in rats. Indian J Clin Biochem 25: 307-310, 2010.

46. Yuan LP, Chen FH, Ling L, Bo H, Chen ZW, Li F, Zhong MM and Xia LJ: Protective effects of total flavonoids of Bidens bipinnata $\mathrm{L}$. against carbon tetrachloride-induced liver fibrosis in rats. J Pharm Pharmacol 60: 1393-1402, 2008.

47. Aviram M, Dornfeld L, Rosenbblat M, Volkova N, Kaplan M, Coleman R, Hayek T, Presser D and Fuhrman B: Pomegranate juice consumption reduces oxidative stress, atherogenic modifications to LDL, and platelet aggregation: Studies in humans and in atherosclerotic apolipoprotein E-deficient mice. Am J Clin Nutr 71: 1062-1076, 2000.

48. Pirinççioğlu M, Kızıl G, Kızıl M, Kanay Z and Ketani A: The protective role of pomegranate juice against carbon tetrachloride-induced oxidative stress in rats. Toxicol Ind Health 30: 910-918, 2014.

49. Garrido C, Gurbuxani S, Ravagnan L and Kroemer G: Heat shock proteins: Endogenous modulators of apoptotic cell death. Biochem Biophys Res Commun 286: 433-442, 2001.

50. Ikeyama S, Kusumoto K, Miyake H, Rokutan K and Tashiro S: A non-toxic heat shock protein 70 inducer, geranylgeranylacetone, suppresses apoptosis of cultured rat hepatocytes caused by hydrogen peroxide and ethanol. J Hepatol 35: 53-61, 2001.

51. Schiaffonati L and Tiberio L: Gene expression in liver after toxic injury: Analysis of heat shock response and oxidative stress-inducible genes. Liver 17: 183-191, 1997.

52. Lee KJ, Terada K, Oyadomari S, Inomata Y, Mori M and Gotoh T: Induction of molecular chaperones in carbon tetrachloride-treated rat liver: Implications in protection against liver damage. Cell Stress Chaperones 9: 58-68, 2004. 